Luise Kiesselbach, Professorenwitwe und Mutter zweier erwachsener Kinder, war 42 Jahre alt, als sie 1906 in Erlangen den Verein „Frauenwohl“ mitbegründete - der Beginn ihres Vollzeit-Engagements als Sozialarbeiterin, Frauenrechtlerin und Sozialpolitikerin. Als viertes von acht Kindern am 28.12.1863 in Hanau geboren, hatte sie mit 15 Jahren schweren Herzens die Schule verlas-

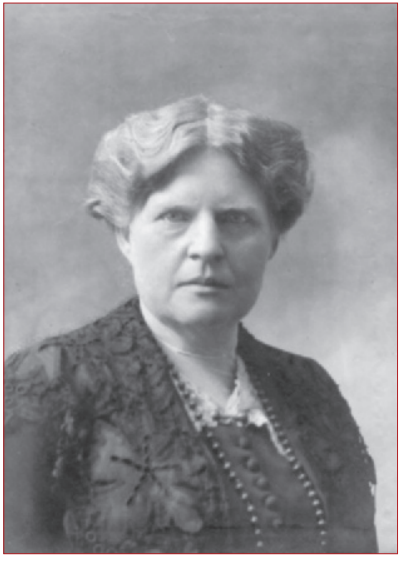
sen und der kranken Mutter geholfen, Haushalt und Geschwister zu versorgen. Zusammen mit anderen bayerischen Frauenvereinen setzte sie jetzt erfolgreich eine zentrale Forderung der Frauenbewegung durch: die Zulassung von Frauen zur Armenpflege. Sie selbst wurde 1909 eine der ersten acht „Hilfsarmenpflegerinnen“ Bayerns. Nach ihrem Erfolg in Erlangen berief man sie 1912 als Vorsitzenden des „Vereins für Fraueninteressen“ nach München. Hier konnte sie sowohl praktisch als auch politisch aktiv sein. Sie sorgte dafür, dass in allen Wohlfahrtsämtern Frauen vertreten waren, richtete Rechtsschutzstellen für Frauen, eine „Berufsberatungsstelle für geistig arbeitende Frauen“ und Heime für obdachlose Kinder und ledige Mütter ein, gründete zahlreiche Hilfsvereine und sorgte dafür, dass diese sich überregional zusammenschlossen. So hat sie u.a. den Münchner wie den Bayerischen Paritätischen Wohlfahrtsverbandes mit gegründet, war in den Gremien der Deutschen Demokratischen Partei vertreten und engagierte sich lokal und national in der Frauen bewegung. 1919 wurde sie in den Münchner Stadtrat gewählt, wo sie in zahlreichen Ausschüssen mitarbeitete und Anfang der zwanziger Jahre - ihrer Zeit weit voraus und leider ohne Erfolg - eine Beschwerdestelle für diejenigen beantragte, „deren Gesuche um Unterstützung ohne zwingenden Grund abgelehnt wurden“. Sie war unübersehbar ein „Workaholic“ - aber bei allem politischen Einsatz immer auch an den Menschen selbst interessiert: „Nicht nur, dass sie mit unwahrscheinlicher Sicherheit immer und trotz aller Hindernisse wieder durchsetzte, was diese Heime brauchten, vor allem waren auch ,ihre Kinder' selbst die ganze Zeit hindurch in ihrer ganz warmen Sorge gebettet. Sie konnte das Schicksal jedes Einzelnen mit der größten Liebe verfolgen" hieß es in einer Sondernummer der Bayerischen Frauenzeitung aus Anlass ihres Todes. Sie starb vor 80 Jahren am 27. Januar 1929, gerade mal 65 Jahre alt. Ihr letztes großes Projekt war ein für damalige Verhältnisse sehr modernes Altersheim mit Einzelzimmern für alle Bewohner. Als Luise-Kiesselbach-Haus (inzwischen an neuem Ort) erinnert es ebenso wie der Luise-Kiesselbach-Platz im Süden Münchens bis heute an diese großartige Frau.

Johannes Herwig-Lempp

\section{Luise Kiesselbach}

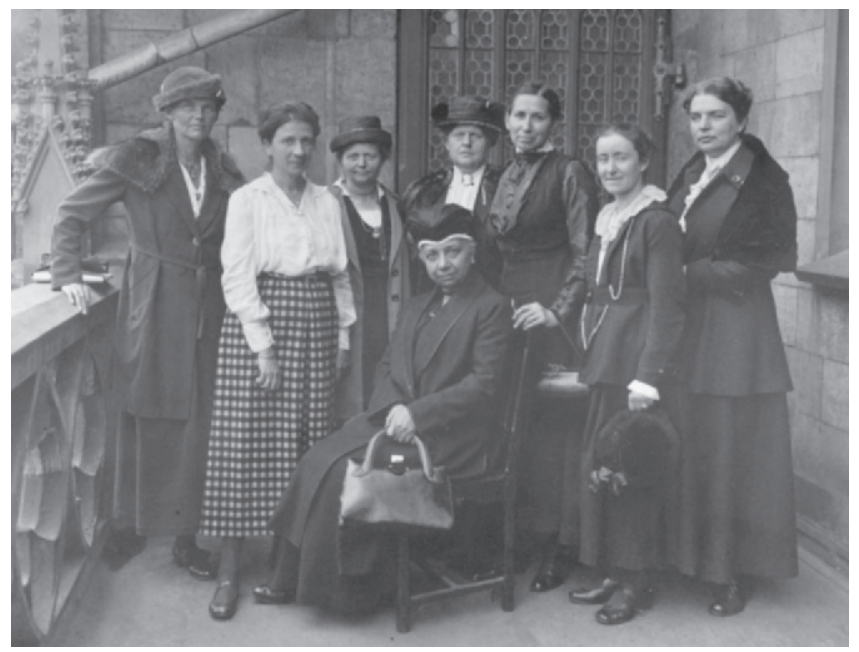

DIE SPITZE DER DEUTSCHEN FRAUENBEWEGUNG 1921 GRUPPENBILD DES VORSTANDSMITGLIEDER DES BUNDES DEUTSCHER FRAUENVEREINE ANLÄSSLICH DER GENERALVERSAMMLUNG 1921 IN KÖLN; V.L.N.R. MARIE ELISABETH LÜDERS, GERTRUD BÄUMER, MARIE BAUM, LUISE KIESSELBACH, ELISABETH ALTMANN-GOTTHEINER, DOROTHEE VON VELSEN, EMMA ENDER, SITZEND ALICE BENSHEIMER (FOTO: HELENE-LANGE-ARCHIV) 